\title{
Effects on management and outcome of severe sepsis and septic shock patients admitted to the intensive care unit after implementation of a sepsis program: a pilot study
}

\author{
Massimo Girardis ${ }^{1}$, Laura Rinaldi1 , Lara Donno1, Marco Marietta², Mauro Codeluppi3, \\ Patrizia Marchegiano4, Claudia Venturelli5 and the 'Sopravvivere alla Sepsi 'group of the Modena- \\ University Hospital
}

\author{
1Department of Anaesthesiology and Intensive Care, University of Modena and Reggio Emilia and University Hospital of Modena; L.go del Pozzo, \\ Modena, 41100, ITALY \\ 2Department of Haematology, University Hospital of Modena; L.go del Pozzo, Modena, 41100, ITALY \\ ${ }^{3}$ Department of Infectious Diseases, University Hospital of Modena; L.go del Pozzo, Modena, 41100, ITALY \\ 4Medical Direction, University Hospital of Modena; L.go del Pozzo, Modena, 41100, ITALY \\ ${ }^{5}$ Microbiology and Virology Unit, University Hospital of Modena; L.go del Pozzo, Modena, 41100, ITALY \\ Corresponding author: Massimo Girardis, girardis.massimo@unimo.it
}

Received: 27 Sep 2008 Revisions requested: 25 Oct 2008 Revisions received: 23 May 2009 Accepted: 3 Sep 2009 Published: 3 Sep 2009

Critical Care 2009, 13:R143 (doi:10.1186/cc8029)

This article is online at: http://ccforum.com/content/13/5/R143

(c) 2009 Girardis et al.; licensee BioMed Central Ltd.

This is an open access article distributed under the terms of the Creative Commons Attribution License (http://creativecommons.org/licenses/by/2.0), which permits unrestricted use, distribution, and reproduction in any medium, provided the original work is properly cited.

\begin{abstract}
Introduction The application in clinical practice of evidencebased guidelines for the management of patients with severe sepsis/septic shock is still poor in the emergency department, while little data are available for patients admitted to the intensive care unit (ICU). The aim of this study was to evaluate the effect of an in-hospital sepsis program on the adherence to evidence-based guidelines and outcome of patients with severe sepsis/septic shock admitted to the ICU.
\end{abstract}

Methods This prospective observational cohort study included 67 patients with severe sepsis/septic shock admitted to a multidisciplinary ICU at a University Hospital from January 2005 to June 2007. Compliance to 5 resuscitation and 4 management sepsis interventions and in-hospital mortality were measured following an educational program on sepsis for physician and nurses of all hospital departments and hospital implementation of a specific protocol for recognition and management of patients with severe sepsis/septic shock, including an early consultation by a skilled 'sepsis team'.

Results During the study period, the compliance to all 9 interventions increased from $8 \%$ to $35 \%$ of the patients $(P<$ 0.01). The implementation of resuscitation and management interventions was associated with a lower risk of in-hospital mortality ( $23 \%$ vs $68 \%$ and $27 \%$ vs $68 \%, P<0.01)$. In the latter 2 semesters, after activation of the 'sepsis team', in-hospital mortality of ICU septic shock patients decreased by about $40 \%$ compared with the previous period (32\% vs $79 \%, P<0.01$ ).

Conclusions In our experience, an in-hospital sepsis program, including education of health-care personnel and processchanges, improved the adherence to guidelines and the survival rate of patients with severe sepsis/septic shock admitted to the ICU.

\section{Introduction}

The high incidence, costs and mortality rate of patients with sepsis in the recent years has led the critical care scientific community to develop specific strategies aimed to improve the outcome of these patients [1-4]. In 2004, the Surviving Sepsis
Campaign (SSC) guidelines [3] recommended a series of diagnostic and therapeutic interventions whose implementation was expected to lead to a survival benefit in patients with severe sepsis/septic shock. Afterwards, to facilitate the application of these guidelines in clinical practice, the Institute for

ALI: acute lung injury; ARDS: Adult respiratory distress syndrome; ED: emergency department; $\mathrm{FiO}_{2}$ : fraction of inspired oxygen; ICU: intensive care unit; IHI: institute for healthcare improvement; MAP: mean arterial pressure; OR: odds ratio; $\mathrm{PaO}_{2}$ : partial pressure of arterial oxygen; rhAPC: recombinant human activated protein C; SAPS: simplified acute physiology score; $\mathrm{ScvO}_{2}$ : central venous oxygen saturation; SOFA: simplified organ failure assessment; SSC: Surviving Sepsis Campaign. 
Healthcare Improvement (IHI) proposed the severe sepsis resuscitation (6-hours) and management (24-hours) bundles, that integrate the interventions described above. Nevertheless, the application of these bundles so far has been demonstrated to be quite poor in most surveys, confirming the difficulty of transferring evidence to the clinical practice [4-12].

The main purpose of our study was to evaluate the effects of a 'surviving sepsis' in-hospital project, including specific educational program and operative protocols, on the adherence to evidence-based guidelines. Moreover, we sought to assess if such a project could improve the outcome of patients with severe sepsis/septic shock admitted to an intensive care unit (ICU).

\section{Materials and methods Design, setting and population}

This prospective observational study enrolled consecutive patients with a diagnosis of severe sepsis/septic shock admitted to an ICU of the 780-bed University Hospital of Modena from January 2005 to June 2007 . The study was approved by the local ethical committee and the need for informed consent was waived in view of the observational and anonymous nature of the study. The ICU consists of nine beds and approximately 800 adult patients are admitted annually $(70 \%$ surgical patients). Staffing at any time consists of one attending physician, one resident physician and three to four nurses.

The inclusion criteria were: a) documented or suspected infection; b) two or more systemic inflammatory response syndrome criteria [13] and c) the onset of an organ dysfunction related to infection: gas exchange impairment (partial pressure of arterial oxygen $\left(\mathrm{PaO}_{2}\right)$ /fraction of inspired oxygen $\left(\mathrm{FiO}_{2}\right)<$ $250 \mathrm{mmHg}$ ), mean arterial pressure (MAP) below $65 \mathrm{mmHg}$, acute renal dysfunction (1.5-fold baseline creatinine increase or urine output $<0.5 \mathrm{ml} / \mathrm{Kg} / \mathrm{h}$ for two hours), total bilirubin above $4 \mathrm{mg} / \mathrm{dL}$, platelet count below 80,000 cells $/ \mathrm{mm}^{3}$ (or a 100,000 cells $/ \mathrm{mm}^{3}$ decrease) or lactate blood concentration above $4.0 \mathrm{mM}$. Patients with persistence of MAP below 65 $\mathrm{mmHg}$ after an adequate fluid infusion (see below) were classified as having septic shock. Patients with severe decompensated chronic liver disease included in the waiting list for liver transplantation were excluded from the study.

\section{Data collection}

Data collection began one month after the start of an in-hospital educational program on sepsis (see below) and only the first episode of severe sepsis/septic shock was considered in each patient. The management of patients was evaluated by analysis of interventions and sepsis bundles [3]. We identified five resuscitation (6-hours bundle) and four management (24hours bundle) interventions: blood cultures collection before antibiotic administration; empiric antibiotic therapy within three hours from diagnosis; control of infection source within six hours; adequate fluid resuscitation before vasopressor administration; central venous oxygen saturation $\left(\mathrm{ScvO}_{2}\right)$ above 70\% within six hours; blood glucose median below 150 $\mathrm{mg} / \mathrm{dL}$ in the first 24 hours; low-dose hydrocortisone administration in association with vasopressor support; recombinant human activated protein $\mathrm{C}$ (rhAPC) if administration indicated; plateau inspiratory pressure below $30 \mathrm{cmH}_{2} \mathrm{O}$ in patients with acute lung injury (ALI)/adult respiratory distress syndrome (ARDS). The term adequate fluid resuscitation indicates a central venous pressure above $6 \mathrm{mmHg}$ (above $8 \mathrm{mmHg}$ if mechanically ventilated) or a global end-diastolic volume by trans-pulmonary thermodilution (PiCCO system, Pulsion, Germany) above $700 \mathrm{ml} / \mathrm{m}^{2}$.

Two of the authors (LR and LD) not involved in the clinical management of the patients, collected the above interventions by analysis of clinical charts and any uncertain data was audit with the attending physician. The interventions were classified as completed and not completed. An intervention not applied because not applicable (e.g. low plateau inspiratory pressure in patient without ALI/ARDS) was defined as completed. The time zero for bundles timing was the time in which the three study inclusion criteria were documented by clinical notes. Type of admission, grade of sepsis, primary site of infection, simplified acute physiology score (SAPS) II and simplified organ failure assessment (SOFA) score the day of sepsis diagnosis [14,15], ICU and hospital length of stay, and hospital mortality were also recorded for each patient. Predicted hospital mortality was calculated by SAPS II score.

\section{Hospital program}

The education phase of our hospital program named "Sopravvivere alla Sepsi nel Policlinico di Modena" (Surviving to Sepsis in Policlinico Hospital of Modena) started on November 2004 and continued throughout the study period. It included basic, advanced and refresh courses with conference lectures and practice training for nurses and physicians of all hospital departments. From November 2004 to June 2007 almost 250 physicians (out of 400) and 300 nurses (out of 950) of our hospital participated in educational courses. A specific protocol for early recognition and management of patients with severe sepsis/septic shock was prepared, approved and promoted (e.g. specific meetings, hospital intra-net, poster displayed in the staff working area) in all hospital wards (June 2006). The protocol includes: i) clinical data needed for severe sepsis/septic shock identification; ii) instruction for 'sepsis team' activation; iii) detailed instructions for early goal directed resuscitation, collection of microbiological samples and antibiotic therapy; and iv) special recommendations on bicarbonate use, low-dose dopamine and glycaemia control. The sepsis team is available 24 hours per day and is formed by two attending physicians: an intensivist and an infectious disease specialist. The team is activated by and collaborates with the attending physician and the nursing department staff in providing the interventions required for each patient with severe sepsis and septic shock (e.g. placing central venous 
line, measuring central venous pressure, providing non-invasive ventilation, assessing for antibiotic strategy and other specific therapy). After the activation by a dedicated telephone number, the time period for team sepsis consultation should be shorter than 60 minutes in patients with severe sepsis and 30 minutes in patients with septic shock. The sepsis team activity (e.g. frequency and percentage of appropriate activation, mean time before consultation, percentage of ICU admission, patient outcome) is regularly recorded and discussed with members of the "Sopravvivere alla Sepsi" group and with the hospital administrators.

\section{Statistical analysis}

The outcome measurements included intervention compliance, ICU and in-hospital length of stay and in-hospital mortality. For data analysis, the study period was divided: in semesters, in order to assess the progression of learning process and in two periods, before and after June 2006, in order to assess the impact of 'sepsis team' on patient outcome. Students' t-test, chi-squared, Fisher's exact test, and analysis of variance single-factor analysis were used when appropriate. Univariate and multivariate logistic regression were performed, with hospital mortality as dependent variable and individual interventions, bundles and sepsis team admission as independent variables. Variables with $P<0.20$ from univariate analysis were included in the backward logistic regression model that was also corrected for possible confounders such as age, SOFA and SAPS II scores, the presence of shock, lactate blood concentration (first data after study inclusion) and sepsis team period. The goodness of fit was assessed by the Hosmer-Lemeshow test. A value of $P<0.05$ was considered significant. The statistical software package SPSS 15.0 (SPSS Inc., Chicago, IL, USA) was used for statistical analysis.

\section{Results}

From January 2005 to June 2007, 87 patients met criteria for study inclusion, but 20 patients were excluded because they were affected by chronic decompensated cirrhosis and were on the waiting list for liver transplantation. Comparing the five semesters of the study period, no differences were observed in the number of patients, age, gender, type of admission (i.e. surgical and emergency department), primary site of infection, SAPS II and hospital length of stay. Percentage of septic shock patients, SOFA score, ICU length of stay and in-hospital mortality decreased $(P>0.05)$ during the study period (Table 1).

The interventions compliance increased $(P<0.05)$ from January 2005 to June 2007 for all but the glycaemia control and adequate fluid resuscitation. In the same way, the compliance with 6-hour resuscitation and 24-hour management bundles as well as with all interventions increased $(P<0.01)$ (Table 2). The implementation of bundles was associated $(P<0.01)$ with a decrease of in-hospital mortality (Figure 1). The charac- teristics of patients with and without all interventions compliance were similar, except for age ( $55 \pm 12$ vs $65 \pm 13$ years), sex (60 vs $27 \%$ female) and SAPS II ( $44 \pm 13$ vs $56 \pm 21 ; P$ $<0.05)$. Nevertheless, the differences between observed mortalities and expected mortalities by SAPS II were favourable ( $P$ $<0.05$ ) in patients with bundles and all interventions compliance (Figure 1).

In-hospital mortality decreased by about $40 \%(P<0.01)$ during the past two semesters (i.e. after 'sepsis team' activation, July 2006 to June 2007) compared with the previous ones (January 2005 to June 2006; Figure 2). Patients of these two study periods were similar in age, type of admission, primary site of infection and SAPS II, but in the two latter semesters SOFA score $(8.4 \pm 3.1)$ and percentage of septic shock patients $(66 \%)$ were lower $(P<0.05)$ than in the earlier three semesters (10.9 \pm 4.2 and $82 \%)$. Considering only septic shock patients in the two study periods, no differences were observed in demographic characteristics whereas the in-hospital mortality decreased $(P<0.01)$ in the two latter semesters (Figure 2).

The univariate logistic regression showed that odds ratio (OR) for in-hospital mortality was reduced $(P<0.05)$ by compliance to infection source control, $\mathrm{ScvO}_{2}$ optimisation, rhAPC administration, 6-hours and 24-hours bundles, all interventions together and team sepsis. Multivariate logistic analysis with adjustment for possible confounders indicated that 6 -hours bundle implementation as well as 24 -hours bundle were independently $(P<0.05)$ associated with lower in-hospital mortality (Table 3 ).

\section{Discussion}

The main findings of our study were that an in-hospital program dedicated to sepsis, including health-care personnel education and specific process changes, improved not only the adherence to evidence-based guidelines in clinical practice, but also the survival rate of patients with severe sepsis and septic shock admitted to the ICU. Also, the adherence to international guidelines provided more appropriate blood cultures, optimization of $\mathrm{SvCO}_{2}$ and adherence to indications for rhAPC, steroids and protective ventilation.

In accordance with the indications of $\mathrm{IHI}$ for the local implementation of the SSC, a few months after the publication of the international guidelines [3] our hospital program started with an educational phase. It involved a large number of physicians and nurses, particularly from those wards implicated in the management of patients with severe sepsis/septic shock. The early establishment of a working group on sepsis, including reference nurses and physicians from all the hospital departments, was a key point in motivating the department staff to an active collaboration. Nevertheless, the high turnover of residents and nurses led to a progressive impoverishment of skilled personnel. To overcome this problem, since 
Table 1

Number, age, sex, primary site of infection, grade of sepsis, severity scores, length of stay and mortality of patients subdivided for semesters

\begin{tabular}{|c|c|c|c|c|c|c|}
\hline Parameters & Total & $\begin{array}{l}\text { January to June } \\
2005\end{array}$ & $\begin{array}{l}\text { July to December } \\
2005\end{array}$ & $\begin{array}{l}\text { January to June } \\
2006\end{array}$ & $\begin{array}{l}\text { July to December } \\
2006\end{array}$ & $\begin{array}{c}\text { January to June } \\
2007\end{array}$ \\
\hline Patients (n) & 67 & 13 & 11 & 10 & 13 & 20 \\
\hline $\begin{array}{l}\text { Age (years; mean } \pm \\
\text { SD) }\end{array}$ & $63 \pm 16$ & $65 \pm 9$ & $69 \pm 13$ & $66 \pm 18$ & $58 \pm 17$ & $61 \pm 20$ \\
\hline Female $(\mathrm{n}, \%)$ & $23(46)$ & $1(8)$ & $3(27)$ & $4(40)$ & $6(46)$ & $9(45)$ \\
\hline ED admissions (n, \%) & $16(24)$ & $1(8)$ & $2(18)$ & $3(30)$ & $4(31)$ & $6(30)$ \\
\hline $\begin{array}{l}\text { Surgical admissions } \\
(n, \%)\end{array}$ & $38(56)$ & $8(61)$ & $8(73)$ & $4(40)$ & $7(54)$ & $11(55)$ \\
\hline \multicolumn{7}{|l|}{$\begin{array}{l}\text { Primary site of } \\
\text { infection }\end{array}$} \\
\hline Pneumonia(\%) & 36 & 38 & 36 & 40 & 31 & 35 \\
\hline Intra-abdominal (\%) & 27 & 15 & 18 & 40 & 38 & 25 \\
\hline Blood (\%) & 15 & 15 & 27 & 0 & 15 & 15 \\
\hline Urinary tract(\%) & 10 & 8 & 9 & 10 & 8 & 15 \\
\hline Surgical wound(\%) & 5 & 8 & 0 & 0 & 8 & 5 \\
\hline Other (\%) & 7 & 15 & 9 & 10 & 0 & 5 \\
\hline Septic shock (n, \%) & $50(75)$ & $11(85)$ & $10(91)$ & $7(70)$ & $9(69)$ & $13(65)$ \\
\hline $\begin{array}{l}\text { Blood lactate }>4 \\
\mathrm{mmol} / \mathrm{L}(\mathrm{n}, \%)\end{array}$ & $28(42)$ & $4(31)$ & $8(73)$ & $3(30)$ & $6(46)$ & $7(35)$ \\
\hline SAPS $($ mean \pm SD) & $53 \pm 21$ & $50 \pm 15$ & $53 \pm 29$ & $61 \pm 24$ & $47 \pm 19$ & $55 \pm 21$ \\
\hline SOFA (mean \pm SD) & $9.7 \pm 3.9$ & $12.3 \pm 4.0$ & $10.1 \pm 4.6$ & $10.1 \pm 4.0$ & $8.4 \pm 3.4$ & $8.4 \pm 2.9$ \\
\hline $\begin{array}{l}\text { ICU LOS (days; mean } \\
\pm \text { SD) }\end{array}$ & $16 \pm 19$ & $24 \pm 33$ & $24 \pm 10$ & $16 \pm 24$ & $16 \pm 17$ & $14 \pm 9$ \\
\hline $\begin{array}{l}\text { H LOS (days; mean } \pm \\
\text { SD) }\end{array}$ & $44 \pm 38$ & $53 \pm 34$ & $31 \pm 38$ & $38 \pm 49$ & $56 \pm 42$ & $42 \pm 25$ \\
\hline $\begin{array}{l}\mathrm{H} \text { mortality overall ( } \mathrm{n} \text {, } \\
\%)\end{array}$ & $33(49)$ & $9(69)$ & $7(64)$ & $7(70)$ & $3(23)$ & 7 (35) \\
\hline $\begin{array}{l}\text { H mortality septic } \\
\text { shock }(n, \%)\end{array}$ & $30(60)$ & $9(82)$ & $8(80)$ & $6(86)$ & $2(22)$ & $5(38)$ \\
\hline
\end{tabular}

$\mathrm{ED}=$ emergency department; ICU = intensive care unit; $\mathrm{H}=$ hospital; $\mathrm{LOS}=$ length of stay; SAPS = simplified acute physiology score; $\mathrm{SD}=$ standard deviation; SOFA = simplified organ failure assessment.

2006 a continuous educational program has been planned as a form of required education for health-care personnel at the hospital.

The compliance to evidence-based interventions at the beginning of the hospital program was very similar to that reported by others in emergency departments (ED) [9-11]. Unfortunately, so far, few data have been reported on the implementation of sepsis bundles in ICU. Ferrer and colleagues [12] recently reported a very low compliance to resuscitation $(5.3 \%)$ as well as management $(10.9 \%)$ bundles before an education program in Spanish ICUs. On the other hand, Gao and colleagues [8] observed in ICU patients a rate of satisfaction of 6-hours sepsis bundles (59\%) higher than that observed in our study. However, in the study by Gao and colleagues the 6-hours resuscitation bundles did not include the assessment and optimization of $\mathrm{ScvO}_{2}$, that is the intervention was more frequently uncompleted in our patients as well as in other studies $[9,11,12]$.

The compliance to evidence-based guidelines increased during the study period and led mainly to an increase of blood culture collection before antibiotic therapy, optimization of $\mathrm{ScvO}_{2}$, steroid use in shocked patients, adherence to indications for rhAPC and protective ventilation. Indeed, adherence to glycaemia control in our experience slightly decreased during the study period probably because of a great concern of 


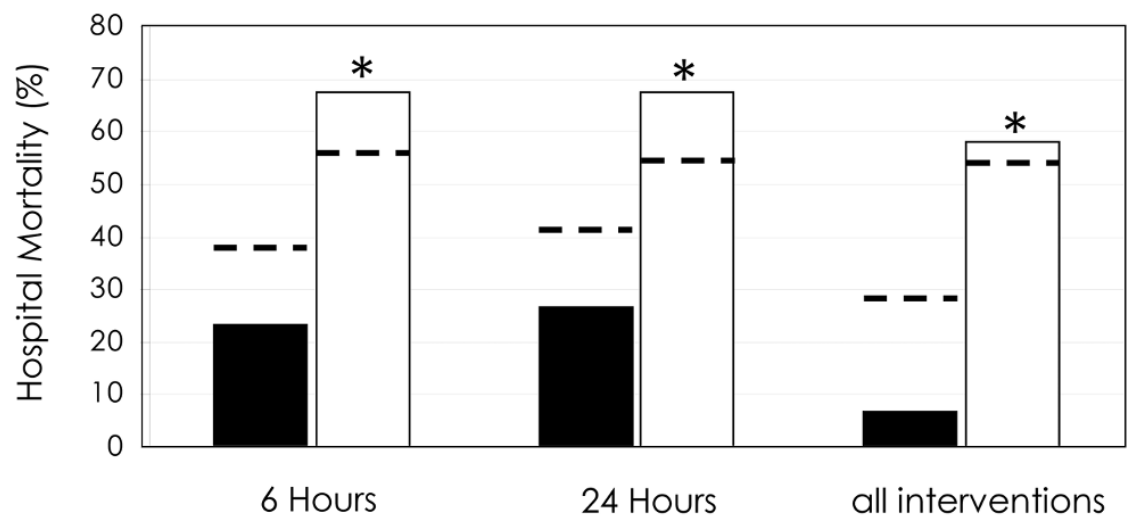

Mortality of patients with (black column) and without (white column) implementation of 6 -hours bundle, 24-hours bundle and all interventions. For each group of patients the predicted mortality by simplified acute physiology score (SAPS) II is also reported (dotted line). ${ }^{*} P<0.05$ comparing patients with and without bundles compliance.

the ICU staff for hypoglycemia-related complications originated by preliminary results of clinical trials [16].

In the latter two semesters, the adherence to 6-hours resuscitation bundles suddenly improved (Table 1). This can be attributed to the activation of process changes in the hospital management of patients with sepsis that provided an early identification and appropriate treatment of patients with organ dysfunction both before and after ICU admission. Nevertheless, also in the last period of the study we were able to complete all the sepsis bundles only in 35 to $40 \%$ of the patients. Numerous activities, besides continuous educational pro-

Table 2

Percentage of patients with completion of interventions and bundles subdivided for semesters of analysis

\begin{tabular}{|c|c|c|c|c|c|c|}
\hline Intervention & Total & $\begin{array}{l}\text { January to June } \\
2005\end{array}$ & $\begin{array}{l}\text { July to December } \\
2005\end{array}$ & $\begin{array}{l}\text { January to June } \\
2006\end{array}$ & $\begin{array}{l}\text { July to December } \\
2006\end{array}$ & $\begin{array}{c}\text { January to June } \\
2007\end{array}$ \\
\hline $\begin{array}{l}\text { Blood cultures } \\
\text { collection* }\end{array}$ & 83 & 77 & 73 & 80 & 92 & 95 \\
\hline $\begin{array}{l}\text { Antibiotic therapy ( } 3 \\
\text { hours)* }\end{array}$ & 95 & 92 & 82 & 100 & 100 & 100 \\
\hline $\begin{array}{l}\text { Infection source } \\
\text { control }^{\star} \S\end{array}$ & 86 & 85 & 82 & 70 & 92 & 100 \\
\hline $\begin{array}{l}\text { Adequate fluid } \\
\text { resuscitation }\end{array}$ & 98 & 92 & 100 & 100 & 100 & 95 \\
\hline $\mathrm{ScvO}_{2}$ optimization* & 61 & 46 & 45 & 50 & 92 & 70 \\
\hline Glycaemia control & 93 & 92 & 100 & 100 & 92 & 80 \\
\hline $\begin{array}{l}\text { Low-dose } \\
\text { hydrocortisone* }\end{array}$ & 73 & 31 & 82 & 80 & 85 & 90 \\
\hline rhAPC* & 66 & 54 & 45 & 70 & 77 & 85 \\
\hline $\mathrm{PiP}<30 \mathrm{cmH}_{2} \mathrm{O}^{*}$ & 79 & 46 & 82 & 80 & 85 & 100 \\
\hline 6-hours bundle & 45 & 38 & 9 & 20 & 77 & 60 \\
\hline 24-hours bundle & 45 & 8 & 36 & 50 & 62 & 60 \\
\hline All interventions & 22 & 8 & 0 & 10 & 46 & 35 \\
\hline $\begin{array}{l}\text { Sepsis team } \\
\text { admissions }^{*}\end{array}$ & 33 & 0 & 0 & 0 & 85 & 55 \\
\hline
\end{tabular}

Data are expressed as percentage of patients. ${ }^{*} P<0.05$ comparing the semesters; $§$ Source control details: 38 surgical patients: 21 control by surgery, 3 radiological drainage, 8 control not necessary, 6 control not achieved within 6 hours. 29 medical patients: 6 radiological drainage, 6 central venous line removal, 13 control not necessary, 4 control not achieved within 6 hours.

$\mathrm{PiP}=$ plateau inspiratory pressure; rhAPC = recombinant human activated $\mathrm{C}$ protein; $\mathrm{ScvO}_{2}=$ central venous oxygen saturation. 
Figure 2

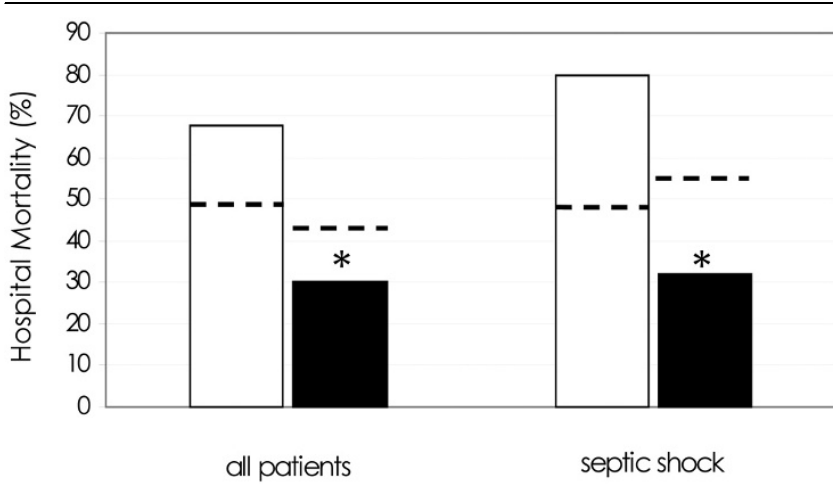

In-hospital mortality before (white columns) and after (black columns) 'sepsis team' activation (June 2006) in all population and in septic shock patients. For each group of patients, the predicted mortality by simplified acute physiology score (SAPS) II is also reported (dotted line). ${ }^{\star} P<0.05$ before and after sepsis team activation.

grams, have been put in action to further improve this result: departmental audit on specific sepsis cases, procalcitonin measurement 24 hours per day and a sepsis dedicated laboratory panel including lactate and the parameters needed for organ dysfunction assessment.

Many studies have indicated that the implementation of interventions recommended by evidence-based guidelines are associated with outcome benefits in severe sepsis patients [5$10,12]$. However, the majority of these studies were carried out in EDs including out-of-hospital patients with community acquired infection. Very few data are available about the effectiveness of this strategy in ICU patients with different provenance (i.e. ED, surgical or medical wards) and type of infection (i.e. community or hospital acquired) $[7,8,12]$. Our data also indicated that in such a setting the compliance to evidencebased interventions improve the outcome of patients with severe sepsis/septic shock. Furthermore, the multivariate analysis including a correction for SAPS II and SOFA scor-, showed that the complete adherence to 6 hours and 24-hours interventions is associated with a significant OR reduction for in-hospital mortality.

As far as single interventions are concerned, the association between $\mathrm{ScvO}_{2}$ of $70 \%$ or more and improved outcome in patients with severe sepsis/septic shock has been widely demonstrated in EDs $[5,10,17]$, but this is the first time that the same figure is reported in ICU patients. Van Beest and colleagues [18] recently reported that the incidence of low $\mathrm{ScvO}_{2}$ in acutely admitted septic shock is very low in Dutch ICUs. In our centre, despite changes in management processes, the incidence of patients with low or unknown $\mathrm{ScvO}_{2}$ within six hours from severe sepsis diagnosis was still around $20 \%$ in the past year. Risks and benefits of rhAPC in patients with severe sepsis/septic shock have been largely discussed and a further discussion on this issue is certainly beyond the aims of this paper. However, we observed that the adherence to the SSC guidelines [3] for the use of rhAPC was associated with a significant decrease in mortality. However, it must be underlined that the number of patients was low and that in the

Table 3

Univariate and multivariate logistic analysis for in-hospital mortality

\begin{tabular}{|c|c|c|c|}
\hline & Odds ratio & $\mathbf{9 5} \%$ confidence interval & $P$ value \\
\hline \multicolumn{4}{|l|}{ Univariate analysis } \\
\hline Infection source control & 0.12 & 0.02 to 0.89 & 0.031 \\
\hline $\mathrm{ScvO}_{2}$ optimization & 0.30 & 0.10 to 0.83 & 0.025 \\
\hline rhAPC & 0.18 & 0.06 to 0.58 & 0.004 \\
\hline 6-hours bundle & 0.17 & 0.06 to 0.50 & $<0.001$ \\
\hline 24-hours bundle & 0.19 & 0.05 to 0.65 & 0.004 \\
\hline All interventions & 0.05 & 0.01 to 0.31 & $<0.005$ \\
\hline Team sepsis activation & 0.28 & 0.10 to 0.79 & 0.015 \\
\hline \multicolumn{4}{|l|}{ Multivariate analysis } \\
\hline 6-hours bundle & 0.15 & 0.03 to 0.63 & 0.010 \\
\hline 24-hours bundle & 0.12 & 0.02 to 0.52 & 0.005 \\
\hline
\end{tabular}

Hosmer-Lemeshow test: $P=0.819$.

rhAPC $=$ recombinant human activated $\mathrm{C}$ protein; $\mathrm{ScvO}_{2}=$ central venous oxygen saturation. 
multivariate analysis none of the single interventions was associated with a significant change in OR for patient mortality.

As discussed above, the institution of a specific team for early sepsis management led to a significant improvement in outcome. This improvement regarded also the septic shock patients, already referred to the ICU before sepsis team institution. One can argue that the improvement could be due to an increased adherence to 24-hours bundle. However, after the sepsis team institution we observed a more remarkable improvement in 6-hours bundle. This suggests that the adopted process changes facilitated a quicker management of shocked patients.

Our study has some limitations. First, the study design (nonrandomized) and the low number of patients involved so far do not allow us to draw any firm conclusions on the effect of single interventions, bundles and process change on sepsis outcome. Second, it has to be considered that the sepsis management model provided and analyzed in our study was according to the 2003 version of the SSC guidelines [4] and, therefore, is in some aspects different to that proposed by the more recent ones [19]. Third, as sepsis team institution and increased bundles compliance occurred simultaneously, we are not able to differentiate the actual role of one in respect to the other on the mortality reduction observed in the past year.

\section{Conclusions}

In conclusion, our single-centre experience demonstrated the importance of specific program addressed to whole hospital departments for improving evidence-based practice and survival rate of patients with severe sepsis/septic shock admitted in ICU. In our model, a multidisciplinary approach and a specific team played a key role for education and for providing an early and appropriate sepsis management. A large number of patients and a more detailed assessment of sepsis team activity before ICU admission appears mandatory for a better understanding of this relevant issue.

\section{Key messages}

- The application in clinical practice of evidence-based guidelines for management of patients with severe sepsis/septic shock is still unsatisfactory.

- An educational program directed to all hospital departments and specific in-hospital process changes for early patient management increased the compliance to sepsis guidelines and led to $45 \%$ absolute risk reduction for in-hospital death in patients with septic shock.

- The institution of a specific sepsis team seems to be a key point for providing the adequate management of inhospital patient with severe sepsis/septic shock.

\section{Competing interests}

MG has consulted for Eli-Lilly Italia; the remaining authors declare that they have no competing interests.

\section{Authors' contributions}

MG has made substantial contributions to study conception and design, data analysis and has been involved in drafting the manuscript. LR has made substantial contributions to study conception and design, acquisition of data, statistical analysis and has been involved in drafting the manuscript. LD has made substantial contributions to study conception and design and acquisition of data. MM has made substantial contributions to study conception and design and has been involved in revising the manuscript for important intellectual content. MC has been involved in revising the manuscript for important intellectual content. PM has made substantial contributions to study conception and design. CV has made substantial contributions to study conception and design and data collection.

\section{Authors' information}

*Members of the 'Sopravvivere alla Sepsi" group of the Modena University Hospital [20]: Baraghini F, Barbieri M, Bonucchi D, Borghi A, Cattani S, Cellini M, Corradi L, Donelli A, Fratti O, Guaraldi N, Leoni P, Lo Fiego E, Malagoli M, Moretti M, Petocchi B, Russo N, Serio L, Tazzioli G, Zito L.

\section{Acknowledgements}

We are grateful to the physicians and nurses of ICU and all hospital departments for their fundamental contribution to the sepsis hospital project. We also thank the educational department and press office of our hospital for supporting the different activities of the project. We are grateful to Mrs Gianna Sassi for the revision of the English manuscript. The study has been supported in part by funds for research fellowships of the University of Modena and Reggio Emilia.

\section{References}

1. Angus DC, Linde-Zwirble WT, Lidicker J, Clermont G, Carcillo J Pinsky MR: Epidemiology of severe sepsis in the United States: Analysis of incidence, outcome and associated costs of care. Crit Care Med 2001, 29:1303-1310.

2. Esteban A, Frutos-Vivar F, Ferguson ND, Peñuelas $O$, Lorente JA Gordo F, Honrubia T, Algora A, Bustos A, García G, Diaz-Regañón IR, de Luna RR: Sepsis incidence and outcome: contrasting the intensive care unit with the hospital ward. Crit Care Med 2007, 35:1284-1289.

3. Dellinger RP, Carlet JM, Masur H, Gerlach H, Calandra T, Cohen J, Gea-Banacloche J, Keh D, Marshall JC, Parker MM, Ramsay G, Zimmerman JL, Vincent JL, Levy MM, Surviving Sepsis Campaign Management Guidelines Committee: Surviving Sepsis Campaign guidelines for management of severe sepsis and septic shock. Crit Care Med 2004, 32:858-873.

4. Karlsson S, Varpula M, Ruokonen E, Pettilä V, Parviainen I, AlaKokko TI, Kolho E, Rintala EM: Incidence, treatment and outcome of severe sepsis in ICU-treated adults in Finland: the Finnsepsis study. Intensive Care Med 2007, 33:435-443.

5. Trzeciak S, Dellinger RP, Abate NL, Cowan RM, Stauss M, Kilgannon JH, Zanotti S, Parrillo JE: Translating research to clinical practice: A 1-year experience with implementing early goal directed therapy for septic shock in the emergency department. Chest 2006, 129:225-232.

6. Shapiro NI, Howell MD, Talmor D, Donnino M, Ngo L, Bates DW: Implementation and outcomes of the Multiple Urgent Sepsis Therapies (MUST) protocol. Crit Care Med 2006, 34:1025-1032. 
7. Kortgen A, Niederprum P, Bauer M: Implementation of an evidence-based "standard operating procedure" and outcome in septic shock. Crit Care Med 2006, 34:943-949.

8. Gao F, Melody T, Daniels DF, Giles S, Fox S: The impact of compliance with 6-hour and 24-hour sepsis bundles on hospital mortality in patients with severe sepsis: A prospective observational study. Crit Care 2005, 9:R764-R770.

9. Micek ST, Roubinian N, Heuring T, Bode M, Williams J, Harrison C, Murphy T, Prentice D, Ruoff BE, Kollef MH: Before-after study of a standardized hospital order set for the management of septic shock. Crit Care Med 2006, 34:2707-2713.

10. Nguyen HB, Corbett SW, Steele R, Banta J, Clark RT, Hayes SR, Edwards J, Cho TW, Wittlake WA: Implementation of a bundle of quality indicators for the early management of severe sepsis and septic shock is associated with decreased mortality. Crit Care Med 2007, 35:1105-1112.

11. De Miguel-Yanes JM, Andueza-Lillo JA, González-Ramallo VJ, Pastor L, Muñoz J: Failure to implement evidence-based clinical guidelines for sepsis at the ED. Am J Emerg Med 2006, 24:553-559.

12. Ferrer R, Artigas A, Levy MM, Blanco J, González-Diaz G, Garnacho-Montero J, Ibáñez J, Palencia E, Quintana M, de la Torre-Prados MV, Edusepsis Study Group: Improvement in process of care and outcome after a multicenter severe sepsis educational program in Spain. JAMA 2008, 299:2294-2303.

13. Levy MM, Fink MP, Marshall JC, Abraham E, Angus D, Cook D, Cohen J, Opal SM, Vincent JL, Ramsay G, International Sepsis Definitions Conference: 2001 SCCM/ESICM/ACCP/ATS/SIS International Sepsis Definitions Conference. Intensive Care Med 2003, 29:530-538.

14. Vincent JL, Moreno R, Takala J, Willatts S, De Mendonça A, Bruining $\mathrm{H}$, Reinhart CK, Suter PM, Thijs LG: The SOFA (Sepsisrelated Organ Failure Assessment) score to describe organ dysfunction/failure. Intensive Care Med 1996, 22:707-710.

15. Le Gall JR, Lemeshow S, Saulnier F: A new Simplified Acute Physiology Score (SAPS II) based on a European/North American multicenter study. JAMA 1993, 270:2957-2963.

16. Brunkhorst FM, Engel C, Bloos F, Meier-Hellmann A, Ragaller M, Weiler N, Moerer O, Gruendling M, Oppert M, Grond S, Olthoff D, Jaschinski U, John S, Rossaint R, Welte T, Schaefer M, Kern P, Kuhnt E, Kiehntopf M, Hartog C, Natanson C, Loeffler M, Reinhart K, German Competence Network Sepsis (SepNet): Intensive insulin therapy and pentastarch resuscitation in severe sepsis. N Engl J Med 2008, 358:125-139.

17. Rivers E, Nguyen B, Havstad S, Ressler J, Muzzin A, Knoblich B, Peterson E, Tomlanovich M, Early Goal-Directed Therapy Collaborative Group: Early goal-directed therapy in the treatment of severe sepsis and septic shock. N Engl J Med 2001, 345:1368-1377.

18. van Beest $P$, Hofstra J, Schultz $M$, van Beest PA, Hofstra JJ, Schultz MJ, Boerma EC, Spronk PE, Kuiper MA: The incidence of low venous oxygen saturation on admission to the intensive care unit: a multi-center observational study in The Netherlands. Crit Care 2008, 12:R33.

19. Dellinger RP, Levy MM, Carlet JM, Bion J, Parker MM, Jaeschke R, Reinhart K, Angus DC, Brun-Buisson C, Beale R, Calandra T, Dhainaut JF, Gerlach H, Harvey M, Marini JJ, Marshall J, Ranieri M, Ramsay G, Sevransky J, Thompson BT, Townsend S, Vender JS, Zimmerman JL, Vincent JL, International Surviving Sepsis Campaign Guidelines Committee; American Association of CriticalCare Nurses; American College of Chest Physicians; American College of Emergency Physicians; Canadian Critical Care Society; European Society of Clinical Microbiology and Infectious Diseases; European Society of Intensive Care Medicine, et al.: Surviving Sepsis Campaign: international guidelines for management of severe sepsis and septic shock. Crit Care Med 2008, 36:296-327.

20. Modena University Hospital [http://www.policlinico.mo.it] 